\title{
Clinical utility gene card for: Tangier disease
}

\author{
Amanda J Hooper ${ }^{1,2,3}$, Sally PA McCormick ${ }^{4}$, Robert A Hegele 5 and John R Burnett ${ }^{\star, 1,2}$ \\ European Journal of Human Genetics (2017) 25, doi:10.1038/ejhg.2017.72; published online 24 May 2017
}

\section{DISEASE CHARACTERISTICS}

1.1 Name of the disease (synonyms)

Tangier disease (familial high-density lipoprotein deficiency; analphalipoproteinemia).

\subsection{OMIM\# of the disease}

205400.

1.3 Name of the analysed genes or DNA/chromosome segments ABCA1.

\subsection{OMIM\# of the gene(s)}

600046 .

\subsection{Mutational spectrum}

The recessive disorder Tangier disease is caused by variants in the ABCA1 gene, which encodes the ATP-binding cassette transporter $1{ }^{1-4}$ This transporter facilitates the efflux of cholesterol from cells to nascent high-density lipoprotein (HDL) particles. The ABCA1 gene consists of 50 exons (49 are coding) spanning 149 kilobases. Loss-offunction variants result in reduced ABCA1 synthesis or activity and demonstrate a reduced cholesterol efflux capacity; loss-of-function missense variants may disrupt binding with apolipoprotein (apo) A-I and trafficking of the ABCAl protein to the plasma membrane. ${ }^{6}$

\subsection{Analytical methods}

Sequencing (Sanger or NGS). The gene includes 49 coding exons and massively parallel sequencing methods may therefore be more costeffective than Sanger sequencing.

\subsection{Analytical validation}

Variant(s) should be confirmed by Sanger sequencing of the relevant region of $A B C A 1$. Correlation of variant status with HDL cholesterol levels within a family may be useful.

1.8 Estimated frequency of the disease (incidence at birth ('birth prevalence') or population prevalence)

If known to be variable between ethnic groups, please report:

With the exception of small founder populations (eg, Tangier Island, Virginia, after which the disorder is named), Tangier disease is very rare. On the basis of allele frequencies of loss-of-function variants (frameshift, nonsense and splicing only; not missense) in the ExAC database, 1 in 400 individuals is heterozygous for a loss-of-function variant, giving Tangier disease a global prevalence of at least 1 in 640000 (Exome Aggregation Consortium; http://exac.broadinstitute. $\operatorname{org} /)$.

\subsection{Diagnostic Setting}

\begin{tabular}{lll}
\hline & Yes & No \\
A. (Differential) diagnostics & $\square$ & $\square$ \\
B. Predictive testing & $\square$ & $\bigotimes$ \\
C. Risk assessment in relatives & $\square$ & $\bigotimes$ \\
D. Prenatal & $\square$ & $\square$
\end{tabular}

Comment: Use of genetic testing is essentially limited to confirmatory diagnosis in a subject suspected to be affected, rather than other applications such as predictive testing or prenatal diagnosis.

\section{TEST CHARACTERISTICS}

\begin{tabular}{|c|c|c|c|c|}
\hline & \multicolumn{2}{|c|}{ Genotype or disease } & \multirow{2}{*}{$\begin{array}{l}\text { A: True positives } \\
\text { B: False positives }\end{array}$} & \multirow{2}{*}{$\begin{array}{l}\text { C: False negative } \\
\text { D: True negative }\end{array}$} \\
\hline & Present & Absent & & \\
\hline \multicolumn{5}{|l|}{ Test } \\
\hline \multirow[t]{2}{*}{ Positive } & $A$ & $\mathrm{~B}$ & Sensitivity: & $A /(A+C)$ \\
\hline & & & Specificity: & $D /(D+B)$ \\
\hline \multirow[t]{2}{*}{ Negative } & $\mathrm{C}$ & $\mathrm{D}$ & Positive predictive value: & $A /(A+B)$ \\
\hline & & & Negative predictive value: & $\mathrm{D} /(\mathrm{C}+\mathrm{D})$ \\
\hline
\end{tabular}

2.1 Analytical sensitivity

(proportion of positive tests if the genotype is present)

Approximately $100 \%$.

2.2 Analytical specificity

(proportion of negative tests if the genotype is not present)

Approximately 100\%.

\subsection{Clinical sensitivity}

(proportion of positive tests if the disease is present)

The clinical sensitivity can be dependent on variable factors such as age or family history. In such cases a general statement should be given, even if a quantification can only be made case by case.

${ }^{1}$ Department of Clinical Biochemistry, PathWest Laboratory Medicine, Royal Perth Hospital and Fiona Stanley Hospital Network, Perth, Western Australia, Australia; ${ }^{2}$ School of Medicine and Pharmacology, University of Western Australia, Perth, Western Australia, Australia; ${ }^{3}$ School of Pathology and Laboratory Medicine, University of Western Australia, Perth, Western Australia, Australia; ${ }^{4}$ Department of Biochemistry, University of Otago, Dunedin, New Zealand; ${ }^{5}$ Departments of Medicine and Biochemistry, Schulich School of Medicine and Robarts Research Institute, Western University, London, Ontario, Canada

${ }^{*}$ Correspondence: Dr JR Burnett, Department of Clinical Biochemistry, PathWest Laboratory Medicine, Royal Perth Hospital and Fiona Stanley Hospital Network, Wellington Street, Perth, Western Australia 6847, Australia. Tel: +61 8 92243121; Fax: +61 8 92241789; E-mail: john.burnett@health.wa.gov.au

Received 6 February 2017; revised 30 March 2017; accepted 5 April 2017; published online 24 May 2017 
Tangier disease is characterised by severe deficiency or absence of HDL in the circulation resulting in tissue accumulation of cholesteryl esters throughout the body, particularly in the reticuloendothelial system. The major clinical signs of Tangier disease include hyperplastic yellow-orange tonsils, hepatosplenomegaly and peripheral neuropathy, which may be relapsing in nature. The clinical expression of Tangier disease, however, is variable. Some patients can present with haematological abnormalities including thrombocytopenia, reticulocytosis, stomatocytes and haemolytic anaemia. Ocular abnormalities include corneal opacities, which are mild and do not impair vision. Tangier disease patients have a moderately increased risk for coronary artery disease, with early coronary heart disease observed in some families, although this is an inconsistent association. ${ }^{7-10}$

\subsection{Clinical specificity}

(proportion of negative tests if the disease is not present)

The clinical specificity can be dependent on variable factors such as age or family history. In such cases a general statement should be given, even if a quantification can only be made case by case.

Approximately $100 \%$.

2.5 Positive clinical predictive value

(life-time risk of developing the disease if the test is positive) $100 \%$.

2.6 Negative clinical predictive value

(probability of not developing the disease if the test is negative)

Assume an increased risk based on family history for a non-affected person. Allelic and locus heterogeneity may need to be considered.

Index case in that family had been tested:

$100 \%$.

Index case in that family had not been tested:

In the setting of an extremely low HDL cholesterol in the absence of hypertriglyceridaemia, artefactual causes (eg, paraproteinaemia) and secondary causes (eg, androgenic anabolic steroids, paradoxical response to PPAR agonists, and malignancy and liver disease) should be excluded. ${ }^{11}$ Like Tangier disease, apo A-I deficiency, familial LCAT deficiency, and fish eye disease are characterised by severe HDL deficiency, however, in the homozygous form, these inherited metabolic diseases can easily be discriminated clinically and biochemically from Tangier disease. However, that is not the case for heterozygotes for apo A-I deficiency and LCAT deficiency, which are typically indistinguishable from those heterozygous for Tangier disease.

\section{CLINICAL UTILITY}

3.1 (Differential) diagnostics: The tested person is clinically affected (To be answered if in 1.9 ' $\mathrm{A}$ ' was marked)

\subsubsection{Can a diagnosis be made other than through a genetic test?}

\begin{tabular}{ll}
\hline No & $\square$ (continue with 3.1.4) \\
Yes & Clinically \\
& Imaging \\
& Endoscopy \\
& Biochemistry \\
& Electrophysiology \\
& Other (please describe)
\end{tabular}

3.1.2 Describe the burden of alternative diagnostic methods to the patient
Tangier disease is characterised by hypocholesterolaemia, extremely low or absent levels of HDL cholesterol (as well as apo A-I and apo A-II), modestly decreased LDL cholesterol and elevated triglycerides in plasma. Two-dimensional gel electrophoresis shows the presence of the pre- $\beta$-HDL subfraction, but the absence of $\alpha$-migrating HDL. Also, cellular cholesterol efflux from fibroblasts is markedly reduced.

Obligate heterozygotes have plasma HDL cholesterol concentrations that are approximately one-half of normal, but are asymptomatic and have no clinical manifestations. Two-dimensional gel electrophoresis shows presence of the pre- $\beta$-HDL subfraction, with detectable, but reduced $\alpha$-migrating HDL along with half-normal fibroblast cholesterol efflux capacity.

\subsubsection{How is the cost effectiveness of alternative diagnostic methods to} be judged?

Not applicable.

3.1.4 Will disease management be influenced by the result of a genetic test?

No

Yes $\otimes$

Therapy (please There is no specific treatment for Tangier disease. describe) Tonsillectomy may be required in case of significant

Prognosis (please Prognosis in Tangier disease is usually good and describe) depends mainly on the progression of peripheral neuropathy. Tangier disease patients have a moderate increased risk of coronary artery disease.

Management (please The clinical follow-up and management of Tangier describe) disease patients should include cardiovascular risk assessment including noninvasive assessment of atherosclerotic plaque burden, together with neurological and ophthalmological examination on an annual basis.

3.2 Predictive Setting: The tested person is clinically unaffected but carries an increased risk based on family history

(To be answered if in 1.9 'B' was marked)

\subsubsection{Will the result of a genetic test influence lifestyle and prevention? \\ If the test result is positive (please describe Not applicable. \\ If the test result is negative (please describe) Not applicable.}

3.2.2 Which options in view of lifestyle and prevention does a person at-risk have if no genetic test has been done (please describe)?

Not applicable.

3.3 Genetic risk assessment in family members of a diseased person (To be answered if in 1.9 'C' was marked)

3.3.1 Does the result of a genetic test resolve the genetic situation in that family?

Not applicable.

3.3.2 Can a genetic test in the index patient save genetic or other tests in family members?

Not applicable. 
3.3.3 Does a positive genetic test result in the index patient enable a predictive test in a family member?

Not applicable.

3.4 Prenatal diagnosis

(To be answered if in 1.9 'D' was marked)

3.4.1 Does a positive genetic test result in the index patient enable a prenatal diagnostic?

Not applicable.

\section{IF APPLICABLE, FURTHER CONSEQUENCES OF TESTING}

Please assume that the result of a genetic test has no immediate medical consequences. Is there any evidence that a genetic test is nevertheless useful for the patient or his/her relatives? (Please describe). Yes; a positive test result for either homozygous or heterozygous status should prompt ongoing monitoring of modifiable cardiovascular risk factors.

\section{CONFLICT OF INTEREST}

The authors declare no conflict of interest.

\section{ACKNOWLEDGEMENTS}

This work was supported by EuroGentest2 (Unit 2: 'Genetic testing as part of health care'), a Coordination Action under FP7 (Grant Agreement Number 261469) and the European Society of Human Genetics.
1 Bodzioch $\mathrm{M}$, Orso $\mathrm{E}$, Klucken $\mathrm{J}$ et al: The gene encoding ATP-binding cassette transporter 1 is mutated in Tangier disease. Nat Genet 1999; 22: 347-351.

2 Brooks-Wilson A, Marcil M, Clee SM et al: Mutations in ABC1 in Tangier disease and familial high-density lipoprotein deficiency. Nat Genet 1999; 22: 336-345.

3 Rust S, Rosier M, Funke $\mathrm{H}$ et al: Tangier disease is caused by mutations in the gene encoding ATP-binding cassette transporter 1. Nat Genet 1999; 22: 352-355.

4 Fu JKS, Sinai L, Abdel-Razek 0 et al: Western Database of Lipid Variants (WDLV): a catalogue of genetic variants in monogenic dyslipidemias. Can J Cardiol 2013; 29. 934-939.

5 Fitzgerald ML, Morris AL, Rhee JS, Andersson LP, Mendez AJ, Freeman MW: Naturally occurring mutations in the largest extracellular loops of ABCA1 can disrupt its direct interaction with apolipoprotein A-I. J Biol Chem 2002; 277 33178-33187.

6 Singaraja RR, Visscher $\mathrm{H}$, James ER et al: Specific mutations in ABCA1 have discrete effects on ABCA1 function and lipid phenotypes both in vivo and in vitro. Circ Res 2006; 99: 389-397.

7 Mautner SL, Sanchez JA, Rader DJ et al: The heart in Tangier disease. Severe coronary atherosclerosis with near absence of high-density lipoprotein cholesterol. Am J Clin Pathol 1992; 98: 191-198.

8 Schaefer EJ, Santos RD, Asztalos BF: Marked HDL deficiency and premature coronary heart disease. Curr Opin Lipidol 2010; 21: 289-297.

9 Schaefer EJ, Zech LA, Schwartz DE, Brewer HBJr: Coronary heart disease prevalence and other clinical features in familial high-density lipoprotein deficiency (Tangier disease). Ann Intern Med 1980; 93: 261-266.

10 Schaefer EJ, Anthanont P, Diffenderfer MR, Polisecki E, Asztalos BF: Diagnosis and treatment of high density lipoprotein deficiency. Prog Cardiovasc Dis 2016; 59: 97-106.

11 Rader DJ, deGoma EM: Approach to the patient with extremely low HDL-cholesterol. J Clin Endocrinol Metab 2012; 97: 3399-3407. 